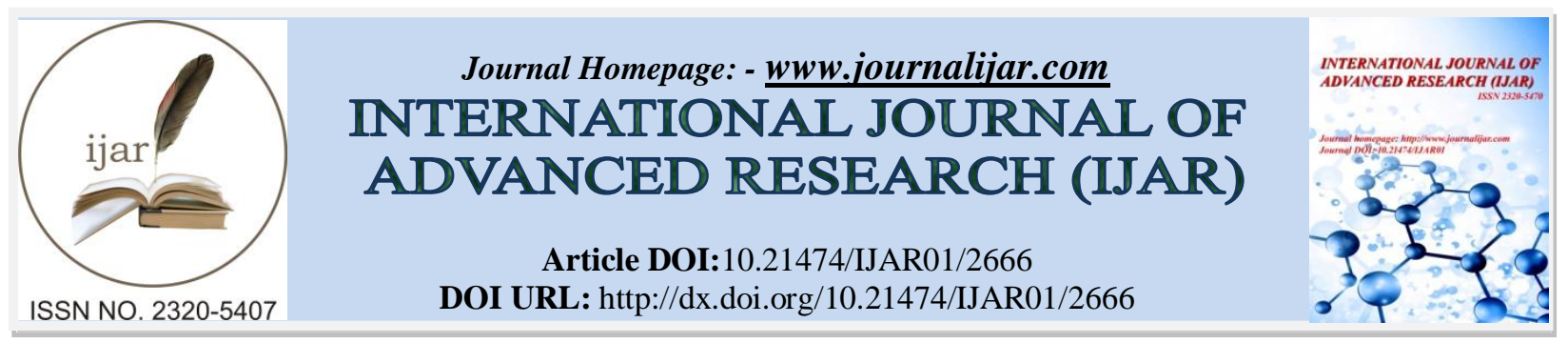

RESEARCH ARTICLE

\title{
COMPARATIVE STUDY OF VEHICLESPEED CONTROLLING SYSTEMS.
}

\author{
Albin Vince ${ }^{1}$, Arnold Tom ${ }^{1}$ and Shaiju Paul ${ }^{2}$. \\ 1. Student CSE Department, Jyothi Engineering College, Cheruthuruthy, Kerala, India. \\ 2. Assistant Professor CSE Department, Jyothi Engineering College, Cheruthuruthy, Kerala, India.
}

\section{Manuscript Info}

\section{Manuscript History}

Received: 31 October 2016

Final Accepted: 30 November 2016

Published: December 2016

Key words:-

Advanced Driver Assistance System (ADAS), RF Technology, GSM modem

\section{Abstract}

This paper looks into recent developments and research trends in various types of speed controlling system used in vehicles. We know that in our day today life the traffic is increasing and we know that the number of accidents happening are also increasing. There are several accidents that cause loss of life because of over speed. Automation of control of vehicle speed is one of the most vital needs of the hour. Usually the drivers drive the vehicles at high speed recklessly in speed limited areas. Even though the traffic police control this vehicles, we cannot achieve full cooperation from them. It is not possible to monitor those areas always to regulate their speed. Depending on the analytic survey of published researches, we will get a clear idea about the necessity of speed controlling system in vehicles.

Copy Right, IJAR, 2016,. All rights reserved.

\section{Introduction:-}

It is known that road accidents are increasing. Most of these accidents are caused because of rash driving of vehicles even at sharp turnings and junctions. Recent studies show that a one third of serious accidents are caused due to over speed of automobiles. Reduction of such accidents is the necessary step to be considered. Many systems have been developed to prevent these road accidents. Therefore, we can reach in conclusion that, an automated system can reduce the chance of accidents on the road.

One major concern was developing an Advanced Driver Assistance System (ADAS) to help the driver in the process of driving. It is a system developed to automate, adapt, and enhance the safety of vehicles and for providing better driving. Safety features consist of traffic warnings, automation of light in night, automate wiper, obstacle detection, keep driver in correct lane, horn control etc.

An ADA system introduced by automotive industry was Cruise control system (CC) that is capable of maintaining speed specified by the driver and its later evolved version Adaptive Cruise Control (ACC) that keeps the vehicle at safer lengths from the preceding vehicle. It was a radar based system which enhances the driving comfort and increases the safety of the vehicle. But these systems have no capability to detect perfectly the curved roads where the speed is to be lowered and controlled to avoid the accidents. Later curve warning systems (CWS) have been developed to recognize and detect the curved roads by using Global Positioning System (GPS) and the digital maps formed from the Geographical Information Systems (GIS) to assess wearyissues.Intelligent speed assistance (ISA) systems warn the driver when the velocity of vehicle is inappropriate, using GPS along with a digital road map containing information about the speed limits. But these systems won't operate in case of unexpected road circumstances (like road work, road diversions, accidents etc.). 
Vehicle-to-vehicle (V2V) communication can further advance the development of ADA systems. Cooperative ACC (CACC) is an advanced version of ACC that adds vehicle-to-vehicle communication, providing the ACC system with more and better information about the vehicle it is following.

\section{Literature survey:-}

According to six literature studies, Radio Frequency (RF) and Global System for Mobile Communication (GSM) are the 2 technologies mainly used for the communication.

RF stands for Radio Frequency. RF signals has ability to travel even when there is an obstruction between transmitter and receiver. RF transmission is better than IR (infra-red) because signals through RF can travel through larger distances making it suitable for long range application. Even though, there are some limitations like difficult weather conditions or blocking by preceding vehicles, RF signals might still be transmitted reliably. RFID technology has been widely accepted now.

GSM modem is a peculiar type of modem which contains a SIM card, and operates over a subscription to a mobile operator and acts just like a mobile phone. From the view of mobile operator, a GSM modem looks just like a mobile phone. When a GSM modem is connected to a computer and allows it to use the GSM modem to communicate over the mobile network. These GSM modems are most frequently used to provide internet connection, many of them can also be used for sending and receiving SMS and MMS messages.

In the system [1] can be used to avoid accidents caused because of curves, humps, hair pin bends and any obstacles preceding the vehicle and also reducing the speed of vehicles by decreasing fuel rate of vehicle. The vehicle speed will be controlled automatically. RF signal is continuously radiated from the transmitters which is tuned at a frequency of $433 \mathrm{MHz}$ for some particular area. As the vehicle come into this area of radiation the receiver in the vehicle gets activate. The coded transmitted signal is encoded with an encoder. A decoder is used for decoding at the vehicle side. The RF transmitter output is of about 400 foot range in outdoors. The receiver can be also operated in 433.92MHz. The disadvantage of this system is the limited range of area the RF can act.

The system [2] is used by the driver about the zones and to automatically maintain the speed, RF technology is used. It is an Electronic Display controller meant for vehicles speed control and monitors the zones and can be custom designed to fit into the dashboard of vehicle to display information on the vehicle. This system can effectively reduce the number of road accidents caused by over speed, losing control of the vehicle at speed breakers or by negligence towards traffic signals. This design is used to control the speed of the automobiles at remote places for fixed time. There are two separate units in this project: Zone status transmitter unit, Electronic Display and Control unit. Once the road-sign signal is received from the zones, the Electronic Display Controller Unit in the vehicle warns the driver, to reduce the speed according to the zone, it waits for response of driver and reduces the speed of vehicle automatically. System controls the vehicle according to the data frame that is transmitted by the RF transmitter fixed to the nearby road signs. The data frame will be received by the microcontroller in automobile which controls the speed of vehicle. This system is a RFID-Based Intelligent vehicle speed controller where passive $\mathrm{RF}$ transmitters and receivers are arranged in the road close to the position of real traffic.

The system [3] automatically alerts the driver according to the zones like accident prone area, heavy traffic area and critical zones. From the dashboard the driver get the information about the speed limit. So the driver will not be distracted. It is a Smart Display controller (SDC) which controls the speed of the vehicle monitors the zones. Here if the driver is not reducing the speed to the limit displayed, the RF signal module can automatically decrease or regulate the speed of the vehicle. This system is available at cheaper rate and consumes less power. Main disadvantage is that once speed is set, it cannot be changed.

The main objective of the system [4] is to operate the vehicle in safe speed at critical zone. The base station having the transmitter which is modeled for frequency modulation (FM), the receiver part is implemented in Vehicle. The ARM processor will be in receiver side, which receives the critical frequency, then it is activated in critical mode. An ARM processor is in the family of CPUs based on the RISC (reduced instruction set computer) architecture which is developed by Advanced RISC Machines (ARM). ARM makes 32-bit and 64-bit RISC multi-core processors. Speed Control Driver (SCD) is designed to fit into a dashboard of vehicle, and displays information on 
the vehicle. Once the information is received, it automatically alerts the driver, to reduce the speed according to the time and zone. When the system initializes the vehicle section, GPS and GSM also gets power. A GSM module sends message to the nearest traffic personnel immediately after violation occurs.

In the system [5] designs a wireless instrument cluster which controls the vehicle in safe speed at critical zones using IEEE 802.15.4 standard. This is done using wireless communication between the vehicle body control unit and instrument cluster unit, together with the sensor unit used for safe distance measurement. Generating a Pulse width modulation in LPC2148 Primer Board at a particular frequency speed of the vehicle can be reduced.

The paper [6] controls the speed of vehicles in cities and restricted areas automatically. It uses RF (Radio Frequency) for indicating the speed limit areas. The controller compares the speed acquired by speedometer and if it exceeds the limited speed it alerts the driver and controls automatically. If they does not respond to the alert an information along with the vehicle number is transmitted to the nearest police station by the use of GSM and fine amount is collected in the nearest toll gate.

\section{Conclusion:-}

This research paper examined different types of vehicle speed controlling systems developed as per the requirements of present traffic scenario. The results in this paper have contributed to understand impacts of ADAS, RF and GSM communication between the vehicle and zones. Nevertheless, some issues are to be noted. First, even though some systems are alerting the drivers. They are not willing to reduce the speed of their vehicle. Second, there are limitations for the interaction between traffic-flow effects and communication and sensor-system characteristics. These characteristics have not been discussed so far.

\section{Acknowledgement:-}

The authors wish to thank our guide Mr.Shaiju Paul and head of the department for providing the facilities to carry out this work.

\section{References:-}

1. Chavan, "Automatic vehicle speed reduction system using RF technology," International Journal of Engineering Research and Applications, vol. 4, 2014.

2. Sattibabu, "Automatic vehicle speed control with wireless in-vehicle road sign delivery system using arm 7," International Journal Of Technology Enhancements And Emerging Engineering Research, vol. 2, 2014.

3. A. Mishra, "Design of rf based speed control system for vehicles," International Journal of Advanced Research in Computer and Communication Engineering, vol. 1, 2012.

4. K.Govindaraju, "Embedded based vehicle speed control system using wireless technology," International Journal Of Innovative Research In Electrical, Electronics, Instrumentation And Control Engineering, vol. 2, 2014.

5. R. Deepa, "Design of vehicle speed control using wireless instrument cluster," International Journal of engineering science and innovative technology (IJESIT), vol. 4, 2015.

6. A.Vengadesh, "Automatic speed control of vehicle in restricted areas using rf and gsm," International Research Journal of Engineering and Technology (IRJET), vol. 2, 2015. 